$R_{\text {esenhas }}$ 


\section{SANTOS, BOAVENTURA DE SOUSA; MENESES, Maria PaUla [orgs.]. EPISTEMOlogias Do SUL. SÃo PAULO: CORTEZ, 2010}

Deolindo de Barros*

Boaventura de Sousa Santos, professor catedrático aposentado da Faculdade de Economia da Universidade de Coimbra, é um prolífico autor e um dos maiores sociólogos da atualidade, tendo já realizado extensas pesquisas sobre as regiões e/ou nações do Sul global, que resgatam e valorizam os conhecimentos, experiências, práticas e saberes próprios dos povos do Sul. Este excelente trabalho organizado juntamente com Maria Paula Meneses, pesquisadora do Centro de Estudos Sociais da Universidade de Coimbra, intitulado Epistemologias do $S u l$, é um dos maiores trabalhos concernentes ao Sul global e uma das maiores contestações aos saberes e valores dominantes do Ocidente; os seus embates contra os saberes orquestrados e impostos pelo colonialismo e capitalismo a serviço do Ocidente são de extrema importância para a historiografia dos povos do Sul.

Como bem argumenta Santos (1995: 508), uma epistemologia do Sul assenta em três orientações: aprender que existe o Sul; aprender a ir para o Sul; aprender a partir do Sul e com o Sul. Sendo assim, após vários anos de pesquisa e articulações com autores das mais

* Doutorando em Ciência Política na Universidade Estadual de Campinas (Unicamp). 
diversas nações do Sul geográfico e metafórico, notadamente aqueles que tomam partido em favor daqueles que são vítimas das mais diferentes e nefastas consequências do domínio colonialista, imperialista e capitalista, assim temos em mãos mais uma obra digna de leitura não apenas para aqueles que navegam na contra-corrente, como igualmente para o leitor mais inteligente.

A obra levanta algumas questões pontuais e muito relevantes: Por que motivo, nos dois últimos séculos, o âmbito cultural e político da produção e reprodução do conhecimento foi suprimido da reflexão epistemológica da epistemologia dominante? Essa descontextualização acarretou quais consequências? Outras epistemologias são hoje plausíveis? Tomando como referência duas ideias, esta obra tenta responder a estas questões. Primeiramente, as epistemologias neutras não existem, e são menos neutras aquelas que tencionam demonstrar essa neutralidade. Subsidiariamente, são nas práticas de conhecimento e nos seus reflexos em outras práticas sociais que a reflexão epistemológica deve debruçar-se, e não nos conhecimentos em abstrato. É com base nessas ideias e noções que devemos analisar e discutir o reflexo do colonialismo e do capitalismo modernos na formação das epistemologias dominantes. Mais do que as dominações geralmente conhecidas, a dominação colonial é igualmente uma dominação epistemológica, o que gerou uma relação bastante iníqua entre saberes, fazendo com que os saberes peculiares dos povos e nações colonizados, bem como diversas outras formas de saber foram suprimidos e inferiorizados.

Devemos ainda frisar que a obra organizada por Santos e Meneses não se limita apenas a indagações, mas sim tenta responder as três questões levantadas. Daí o livro sugere as epistemologias do Sul como alternativa, de modo a não ficar circunscrito a uma crítica simples. É esse manancial e essa série de intervenções epistemológicas que indagam a respeito das condições de um diálogo horizontal entre saberes (ecologia de saberes), valorizam os conhecimentos que obtiveram sucesso na 
sua resistência, bem como as reflexões que tais saberes produziram, e mostram como a epistemologia dominante fez sucumbir outros modos de saber nesses últimos séculos, é que se denomina genericamente de epistemologias do Sul.

Os organizadores da obra assinalam que as epistemologias do Sul podem ser entendidas como a diversidade epistemológica do mundo. Tentando reparar os danos e impactos historicamente causados pelo capitalismo na sua relação colonial com o mundo, o Sul é aqui entendido metaforicamente como um campo de desafios epistémicos. De certa forma, esta noção de Sul vai ao encontro do Sul geográfico, ou seja, aqueles lugares e países do mundo que foram colonizados pelas potências européias, e por isso não lograram os mesmos desenvolvimentos econômicos do Norte global (Europa e EUA designadamente), salvo, notadamente, a Austrália e a Nova Zelândia (a Oceania, por assim dizer). Entretanto, este alinhamento da concepção do Sul e do Sul geográfico não é total, na medida em que o Norte geográfico tem o seu "terceiro mundo interior" e o Sul geográfico sempre teve as suas "pequenas Europas", as suas "Europas internas". Isto é, os muçulmanos, os indígenas, os trabalhadores migrantes, as mulheres, os afro-descendentes, os ciganos, etc, constituem grupos e classes sociais bastante vastos que sofrem os reflexos do colonialismo e do capitalismo no interior do Norte global, enquanto que pequenas elites locais beneficiaram e continuam a beneficiar com a dominação colonial e capitalista no Sul global, subalternizando assim outros grupos e classes sociais. A noção básica é que além das dominações por que é geralmente conhecido o colonialismo, ele estende os seus tentáculos a outros domínios e esferas nem sempre vistos como coloniais, fazendo desaparecer conhecimentos específicos dos povos e nações colonizados. Ou seja, o colonialismo é uma relação extremamente iníqua de saber-poder, uma dominação epistemológica. A investigação das condições de um diálogo horizontal entre saberes, a valorização dos saberes que resistiram com sucesso e a denúncia da supressão dos saberes próprios dos povos colonizados é que se designa por 
epistemologias do Sul. As ecologias de saberes são justamente esse diálogo entre diferentes formas de saberes/conhecimentos.

Ainda que não denominem como epistemologias do Sul as suas pesquisas, de um modo ou outro, os autores presentes nesta obra compartilham as finalidades deste conceito/proposta. Vejamos que a esmagadora maioria deles é originária do Sul geográfico (África, América Latina, Ásia), e defendem as propostas e os interesses do Sul metafórico no interior de cada uma dessas regiões do mundo, defendendo a causa daqueles que sofrem os impactos e os reflexos do colonialismo e do capitalismo, bem como do colonialismo interno, isto é, do poder racista/etnicista que opera no interior de um Estado-nação, para usar a expressão de Pablo González Casanova (1965) e Rodolfo Stavenhagen (1965).

Para além da introdução, a obra encontra-se dividida em quatro partes. Da Colonialidade à Descolonialidade traduz-se na primeira parte, e analisa como a construção de hierarquias entre saberes foi resultado da dominação econômica, política e cultural, isto é, algumas das diretrizes básicas da distinção epistemológica.

As Modernidades das Tradições constitui(em) a segunda parte da obra, em que focaliza a dicotomia entre tradição e modernidade, isto é, as dicotomias fundamentais em que foi entornada a diferença epistemológica. A denominação de saberes tradicionais ou restos de um passado sem futuro aparece como resultado da subalternização dos saberes não-ocidentais. Paradoxalmente, tanto os saberes designados como modernos, como os designados como tradicionais foram investidos de modernidade pela dicotomização dos conhecimentos que foi um ato moderno - eis o objetivo desta parte. Os saberes tradicionais devem ser tratados como modernidades alternativas, na medida em que se mostraram modernos no modo como opuseram ao saber hegemônico.

A terceira parte da obra intitula-se Geopolíticas e a sua Subversão. Esta parte trata da formação do conhecimento moderno hegemônico e o aprofundamento dos lugares e contextos que se 
encontram na sua origem, e para os saberes desqualificados/ inferiorizados, bem como para as práticas e agentes sociais que os produziam e reproduziam, que significação isso teve. A valorização dos saberes até agora desqualificados como locais, ou seja, como contextuais e a identificação da diversidade epistemológica do mundo, são facilitados pela pluralidade dos lugares e contextos.

As Reinvenções dos Lugares, voltando-se aos lugares para sugerir a sua reinvenção, traduz-se na quarta e última parte dessa obra. A noção básica é que a riqueza dos lugares sempre se viu reduzida e limitada pela definição hegemônica/predominante dos lugares de produção de conhecimento, a iniciar-se pela dos lugares da modernidade capitalista ocidental. Para tornar credível quer a superioridade do saber que se queria infundir, quer a subalternidade do saber que se queria eliminar, a diversidade epistemológica de cada um deles (lugares) foi suprimida. A pauperização epistemológica tanto do Norte global como do Sul global, ainda que com corolários muito diferentes para um e para outro, como resultado da imposição da distinção epistemológica orquestrada pelo colonialismo e pelo capitalismo modernos, é o que tenciona mostrar a reinvenção dos lugares.

A obra compensa e é frutífera em termos de riqueza conceitual e analítica, contribuindo peremptoriamente para os campos de estudo da epistemologia, da teoria pós-colonial, dos movimentos sociais, da democracia, etc., ao demonstrar uma cosmovisão condizente com os anseios e as expectativas das classes, grupos sociais e sociedades do Sul global, como a brasileira por exemplo. Além disso, os autores apresentam colocações contundentes e afirmativas a respeito do reconhecimento, qualificação e valorização dos conhecimentos, saberes, práticas e experiências dos povos do Sul, posicionando-se neutra e claramente num certo lugar do mundo das reflexões/idéias.

Para finalizar, uma das características marcantes deste livro organizado por Boaventura de Sousa Santos e Maria Paula Meneses, é o fato da obra levantar novos questionamentos, provocar inquietações, gerar expectativas e abrir novos horizontes 
de pesquisa, de modo a despontar no leitor novas possibilidades de abordagens e interpretações, deixando-o deste modo munido de novas ferramentas de pensamento e contestação dos paradigmas impostos e transmitidos pela modernidade capitalista.

Santos e Meneses argumentam que confrontando as fundações das relações epistêmicas modernas, coloniais e imperiais, esta obra polemiza os sentidos e as explicações epistemológicas dominantes/hegemônicas. Articulando de modo sólido as diversas perspectivas críticas à epistemologia moderna, constituídas a partir de distintos lugares e disciplinas, este livro auxilia, assim, na descolonização do saber. Incluindo, após a reconfiguração, as experiências de conhecimento do Norte global, as epistemologias do Sul traduzem-se num convite a um vasto reconhecimento das experiências de conhecimento do mundo. Novas formas de diálogo e pontes indiscutíveis de intercomunicação são deste modo estabelecidas. Mesmo consciente de que a "versão completa e integral" é impossível, o mundo não se pode satisfazer com breves resumos de si próprio, nem no âmbito epistemológico, nem em outros contextos. Para que a intencionalidade e a compreensão das práticas sociais seja a mais abrangente, justa e democrática possível, a energia deve focalizar-se na valorização da diversidade de saberes, no diálogo horizontal entre as diferentes formas de conhecimento (ecologia dos saberes). 